\title{
Electrolyte Replacement Agent
}

National Cancer Institute

\section{Source}

National Cancer Institute. Electrolyte Replacement Agent. NCI Thesaurus. Code C29730.

Any agent or mixture of agents that are used to replenish electrolytes in body fluids, such as sodium, potassium, calcium, magnesium, phosphorus, chloride and bicarbonate. 